\title{
TRAIT EMOTIONAL INTELLIGENCE OF TEACHERS WORKING IN SPECIAL EDUCATION SCHOOLS
}

\author{
Simas Garbenis \\ Vilniaus universiteto Šiaulių akademija, Lithuania
}

\begin{abstract}
Today's schools are constantly engaged by various new experiences, challenges, difficulties and opportunities. Nowadays it is well known that for a school to be successful in both academic and social development it must be opened to use new strategies and methods in order to adapt to these constantly upcoming challenges. It is known that students with special educational needs usually find it harder to function socially, academically, they also tend to undervalue their quality of life. In recent years it has been discovered that student emotions can play a huge part for one's development in the mentioned areas. In order to fully understand and dispose emotional powers one must be emotionally intelligent. In recent decades research has revealed that emotional intelligence can play a key role to increase the potential of students with special educational needs. These children usually struggle to socially adapt and communicate, to create new relationships, tend to be emotionally unstable, etc. It is also stated that in order to develop student's emotional intelligence teachers should be highly emotionally intelligent as well as emotional intelligence is developed through social interactions, and the control of social interactions in the emotional level. Thus, the development of their emotional intelligence in a school environment is majorly important, especially if this kind of development is being conducted by highly emotionally intelligent teachers. It is because of these statements the aim of this study has been formulated - to evaluate the trait emotional intelligence of primary school teachers who work in special education schools. In order to reach this goal several research questions were raised: what are the global EI and its factor scores of our sample, how do these scores distribute between themselves, how do they contribute for the development of EI? Also, several research methods were used. A sample of 66 primary education teachers who work in special education schools form Lithuania and Latvia were asked to answer the TEIQueSF questionnaire. Their scores were evaluated according to the questionnaires scoring key. Their score validity was conducted by using Cronbach's alpha score and KMO factorial analysis scores all by using SPSS v23. Although the Cronhach's alpha and KMO scores show no significant research data it has been partly discovered that the teacher's from our sample global emotional intelligence score should be at a higher than intermediate-high level.
\end{abstract}

Keywords: emotions, primary education, special education, special educational needs, trait emotional intelligence. 


\section{Introduction}

In recent decades the concept of emotions and even more so the concept of emotional intelligence has been increasing in interest as a research object for various field researcher's (Humphrey et al., 2007; Parker et al., 2009; Keefer et al., 2018). Nowadays emotional intelligence and it's possible influence in various educational-based researches is becoming more and more popular and substantial (Gershon \& Pelliteri, 2018; Petrides et al., 2018). As researchers Alam, Ahmad (2018), Valente, Lourenco (2020) suggest that teachers can play a key role in their students` emotional intelligence development, because highly emotionally intelligent teachers are more effective in classroom stress management, empathy engagement, relationships, etc. This importance is especially distinguished in special education. Children with special educational needs (SEN) tend to have lower emotional intelligence scores than their peers without SEN. Children with lower emotional intelligence powers find it hard to perceive their own and other people's emotions, focus during classes, effectively function during various social interactions, are less empathetic, etc. (Mavroveli and Sanchez-Ruiz, 2011; Kumar, 2013; Boily et al., 2017). These statements suggest that highly emotionally intelligent teachers should be effective emotional intelligence "developers" for such children. Emotional aspects in the teaching process influence overall student performance, which has been proved in many studies (Brackett et al., 2011; Li et al., 2018; Romano et al., 2020). This means that highly emotionally intelligent teachers throughout their relationships with such children could be highly beneficial not only in various educational contexts, but other life areas, the quality of life overall.

Despite this possible potential there is a significant gap in knowledge regarding teachers who work with children who have SEN emotional intelligence scores. Most researches are focused towards relationship and correlation analysis between emotional intelligence and other aspects that are important in such work (Poedubicky et al., 2006; Yahyazadeh-Jeloudar, Lotfi-Goodarzi, 2012; Lestari, Sawitri, 2017).

A simple emotional intelligence evaluation of such teachers could generate highly valuable recommendations and insights for their personal and professional development, their students emotional intelligence development potential.

\section{The concepts of emotional intelligence}

It is worth to mention that because of the increase of these type of researches the increase in popularity of different emotional intelligence concepts emerges as well (Drigas, Papoutsi, 2018; Fiori, Vesely-Maillefer, 2018; Petrides et al., 2018). In order to fully understand what is emotional 
intelligence and how can it be beneficial it is crucial to have a holistic understanding of various emotional intelligence concepts. As it is stated in scientific literature there are four main concepts (theories) of emotional intelligence: 1) D. Goleman's concept; 2) Bar-On's concept; 3) ability concept; 4) trait concept (Petrides \& Furnham, 2001; Goleman, 1995; Salovey \& Mayer, 1990; Bar-On, 2006). The later two concepts are considered the most widely used in order to conducted emotional intelligence related researches in educational contexts. Although these two concepts might seem similar, they define and measure emotional intelligence differently (Petrides, 2017). The ability emotional intelligence concept concerns emotion-related cognitive abilities. In other words, the ability concept operanalizes emotional intelligence as a constellation of abilities to fully use one's emotional powers in order to generate thoughts. Whilst the trait concept of emotional intelligence interprets emotional intelligence as an emotional self-efficacy. This means that the trait concept of emotional intelligence offers to understand emotions as experiences (Petrides, 2011). In a broad sense emotional intelligence can be defined as a constellation of traits to use one's emotional powers to the maximum potential. Both of these constructs are widely used in educational researchers, yet for this research the later concept was chosen for several main reasons (Siegling et al., 2015):

1) trait emotional intelligence has a more robust and refined research tool suitable for various samples (TEIQue, TEIQue-SF, TEIQue-360, etc.);

2) other similar research tools like the MCEIT does not prove to measure any type of intelligence rather separate abilities;

3) emotions are subjective and the TEIQue-SF offers a subjective evaluation of one's emotional traits. Note that this concept is to be considered and kept in mind when emotional intelligence is mentioned.

\section{The importance of emotional intelligence for children with special educational needs}

Several researchers have revealed the benefits of development of emotional intelligence for early year scholars. Mavroveli and Sanchez-Ruiz (2011) discovered that scholars with higher scores of emotional intelligences are related to more peer nominations for prosocial behaviours, fewer for antisocial behaviours. Other researchers (Gershon \& Pelliteri, 2018) found that the development of emotional intelligence in schools, especially in early years, can have a positive impact on scholar social skills, antisocial behaviour, substance abuse, positive self-image, academic achievement, mental health, prosocial behaviour, general well being overall. Although it is worth to mention that there is no difference between the trait emotional intelligence structure between children who have special educational 
needs (SEN) and normally developing children. This means that all children can benefit from the development of emotional intelligence, but children with SEN can benefit more due to several reasons.

First of all, as several researches would suggest, children with SEN score significantly lower on emotional intelligence evaluation scores (Mavroveli and Sanchez-Ruiz, 2011; Kumar, 2013; Boily et al., 2017). Second of all, such students have difficulties functioning effectively during everyday tasks. Children with SEN tend to see and perceive their surroundings differently than normally developing children, they also are unable to sit still during classes, finish tasks, plan ahead or show a broader perspective of interest (Kumar, 2013). According to Kumar (2013) such development for children with SEN should help them understand their own emotions, take more responsibility for their life, respect the emotions of others more, to accept reality, choose consciously, avoid emotional hijackings, learn to create a state of "flow" improve their relationships, become more positive.

All in all, every single child and scholar can benefit from the development of one's emotional intelligence. Yet for several reasons mentioned earlier children with SEN might benefit from it significantly more.

\section{Teachers as emotional intelligence developers}

It is no secret the scholars spend most of their time in schools and other educational organizations. This aspect alone forms a nearly perfect environment and opportunity to develop children with SEN emotional intelligence. Yet there are several guidelines to keep in mind.

Firstly, and perhaps most importantly, is that the teachers working with this object must be highly emotionally intelligent themselves. In current scientific literature there is a lack of research based on the relationship between teachers social-emotional, professional competence and difficulties experienced while working with students with SEN. Despite the various and different teaching challenges that teachers meet depending on the type and level of SEN teachers will surely need to find several strategies and methods on how to pass their knowledge for such students, adapt to their needs, learn to work with them effectively, etc. (Skura \& Swiderska, 2021). In other words, teachers who work with such students must be able to find ways to communicate with them in a most effective manner. This statement suggests that a highly emotional teacher should be successful when dealing with such challenges. Researchers (Armour, 2012; Valente, Lourenço,, 2020) suggest that teachers who are less emotionally intelligent are also less likely to be successful in developing relationships with such students, maintaining classroom discipline, progressing as education specialists. This means that in order to effectively communicate and understand children with SEN teachers must be highly emotionally intelligent. 
Secondly, Emotional intelligence can be developed through the (self-) educational process. As mentioned earlier in order for teachers to develop the emotional intelligence of children with SEN they must constantly communicate. This means that students and teachers will experience various emotions during a wide range of different social interactions. Therefore, proper student-teacher communication is of great importance for the manifestation and management of students' emotions (Grams, Jurowetzki, 2015). The aspects of a highly emotionally intelligent teacher and his abilities to control social interactions with students with SEN in order for them to learn and develop various traits creates a nearly perfect educational environment for the development of emotional intelligence (Mainhard, et al., 2018).

Based on these statements it is conducted that teachers themselves can be very effective partners, guides and even tools for students with SEN in order to develop their emotional intelligence. That is why it is crucial to evaluate such teacher emotional intelligence scores and perhaps generate some conclusions involving future teacher professional development dilemmas.

\section{Methodology}

This quantitative study design consisting of 4 main stages; 2 data gathering methods, 3 data analysis methods, a sample of teachers who work in special education schools has been shaped in order to achieve this study's aim - to evaluate the trait emotional intelligence of primary school teachers who work in special education schools.

The study was conducted between 2021-02 and 2021-05. The first stage of the study was a scientific literature analysis stage. The main aim of this stage was to create a robust theoretical framework for the study design and theoretical validation. After this stage was completed the second stage or the sample generation phase took place. According to the analysis of scientific literature it was determined to consist a sample of teachers who work in special education schools (primary education teachers). After determining the sample needed for the study appropriate entries were invited to take part in the study, thus marking the beginning of data gathering stage. A virtual questionnaire was sent out to all the teachers who agreed to take part in the study. Lastly, after gathering all the necessary data the fourth and final stage took place. The data analysis phase consists all of the mathematical statistical methods that were necessary to reach the study goal and to answer the research questions. 
Several methods were used to form the research design and to require all the necessary data. Methods that allowed to gather all the necessary data for the study:

1) A method of scientific literature analysis. This method was used to form the theoretical framework for the upcoming empirical work of this study.

2) A questionnaire developed by Petrides (2009) TEIQue-SF (https:// www.psychometriclab.com/adminsdata/files/The\%20TEIQue-SF\%20 v.\%201.50.pdf) was used to gather the main empirical data regarding the sample's global emotional intelligence and it's factor scores. This 30 -item form includes two items from each of the 15 facets of the TEIQue. Items were selected primarily on the basis of their correlations with the corresponding total facet scores, which ensured broad coverage of the sampling domain of the construct. The -SF can be used in research designs with limited experimental time or wherein trait EI is a peripheral variable.

After recoding the raw data fallowing the questionnaire's key guidelines several data analysis methods were used: 1) a mathematical method of statistical average scores (mean) was used to evaluate the sample's global EI score and it's factor scores. A mean between 1 (very low) and 7 (very high) was generated. 2) to validate the statistical internal consistency of these scores a Cronbach's alpha score was generated. This score was used to determine how reliable the data truly is, since the sample filled a questionnaire of a foreign language. 3) to identify if there are any underlying factors in the data factor a KMO factor analysis has been conducted. This score was used to determine if the factor analysis will be of any use for the study. These processes were conducted using a SPSS v.23 program.

The empirical part of this study firstly consisted of 89 primary education teachers from Lithuania and Latvia. These teachers were selected according the following criteria: they must be currently working with children with SEN, they are currently working in a primary education field, they are primary school and not single discipline teachers. Valid entries were asked to participate in the study by completing a trait emotional intelligence evaluation questionnaire TEIQue-SF (English version). 66 ( $N=13$ from Latvia, $N=53$ from Lithuania) of 89 were considered as valid entries based on their TEIQue-SF answer quality (questionnaires with skipped, non-deferential, linear answer patterns, etc. were excluded).

The first sample of 89 teachers were introduced with this study's ethical parameters. The sample was informed that neither their names, surnames, any other personal data, workplace, etc., will be visible and used in the final manuscript of this study. They were also asked to participate in this study solely on their free will and granted the right to leave the study if 
they wished to do so. No one from the sample decided to leave the research nor they informed the researcher of any ethical violations.

\section{Results}

Table 1 represents the main and most important results of this research. The average score (mean) represents the level of participant global emotional score and it's factor score. These scores vary from 1 (meaning very low) to 7 (meaning very high). This table also specifies the maximum and minimum score obtained for each factor. These results specify that the global EI of the study sample can be described as above average. Also, several EI facets (well-being, emotionality) can be evaluated like-wise. The remaining facets are scored significantly lower, below average.

Table 1. Participant factor score distribution according based on descriptive analysis

\begin{tabular}{|c|c|c|c|c|c|}
\hline Factors & $\begin{array}{l}\text { Number of } \\
\text { participants }\end{array}$ & $\begin{array}{l}\text { Minimum } \\
\text { score } \\
\text { (mean) }\end{array}$ & $\begin{array}{l}\text { Maximum } \\
\text { score } \\
\text { (mean) }\end{array}$ & $\begin{array}{l}\text { Average } \\
\text { score } \\
\text { (mean) }\end{array}$ & $\begin{array}{l}\text { Std. } \\
\text { Deviation }\end{array}$ \\
\hline Global EI & \multirow[t]{5}{*}{66} & 4.10 & 6.30 & 5.14 & .56 \\
\hline Well-being & & 4.33 & 7.00 & 5.73 & .65 \\
\hline Emotionality & & 3.38 & 6.75 & 5.22 & .74 \\
\hline Self-control & & 2.83 & 6.83 & 5.03 & .80 \\
\hline Sociability & & 2.33 & 6.17 & 4.60 & .82 \\
\hline
\end{tabular}

Table 2 is set to represent the validity and reliability of the scores that were obtained. Note that these scores cannot be considered neither reliable nor significant or valid hence the Cronbach's Alpha score with a sample of 66 should be around .9-1.0. Adjacently, results are met with the KMO factor score, which should be between .8-1.0.

Table 2. Factor score validity and reliability scores based on descriptive analysis

\begin{tabular}{|l|l|l|}
\hline & $\begin{array}{l}\text { Cronbach's } \\
\text { Alpha score }\end{array}$ & $\begin{array}{l}\text { KMO factor } \\
\text { analysis score }\end{array}$ \\
\hline Global EI score & .783 & .530 \\
\hline Well-being score & .348 & .572 \\
\hline Self-control score & .449 & .573 \\
\hline Emotionality score & .523 & .599 \\
\hline Sociability score & .450 & .509 \\
\hline
\end{tabular}


These results suggest that the items that should be closely related to one another in order to forma single EI facets are not well grouped. This means that this set of data cannot be considered as trustworthy. Furthermore, the KMO factor is also low, signalling a poor value for a factor analysis. It is worth to mention that the global EI score has a Cronbach's alpha score of .78. considering that the global EI score is consisted of 30 items this score in order to be significant should be just above .8 .

Table 3 represents the component distribution in each factor of the emotional intelligence traits.

Table 3. Factorial component distribution of trait EI factors

\begin{tabular}{|c|c|c|c|c|c|c|c|c|c|}
\hline \multirow{2}{*}{$\begin{array}{l}\text { Com- } \\
\text { po- } \\
\text { nent }\end{array}$} & \multicolumn{3}{|c|}{ Initial Eigenvalues } & \multicolumn{3}{|c|}{$\begin{array}{l}\text { Extraction Sums of } \\
\text { Squared Loadings }\end{array}$} & \multicolumn{3}{|c|}{$\begin{array}{l}\text { Rotation Sums of } \\
\text { Squared Loadings }\end{array}$} \\
\hline & Total & $\begin{array}{l}\% \text { of } \\
\text { Vari- } \\
\text { ance }\end{array}$ & $\begin{array}{l}\text { Cumu- } \\
\text { lative } \\
\%\end{array}$ & Total & $\begin{array}{l}\% \text { of } \\
\text { Vari- } \\
\text { ance }\end{array}$ & $\begin{array}{l}\text { Cumu- } \\
\text { lative } \\
\%\end{array}$ & Total & $\begin{array}{l}\% \text { of } \\
\text { Vari- } \\
\text { ance }\end{array}$ & \begin{tabular}{|l} 
Cumu- \\
lative \\
$\%$
\end{tabular} \\
\hline \multicolumn{10}{|c|}{ Global EI factor distribution } \\
\hline 1 & 4.8 & 16.1 & 16.1 & 4.8 & 16.0 & 16.0 & 3.6 & 12.0 & 12.0 \\
\hline 2 & 2.5 & 8.3 & 24.4 & 2.5 & 8.3 & 24.4 & 3.1 & 10.3 & 22.2 \\
\hline 3 & 2.2 & 7.4 & 31.8 & 2.2 & 7.4 & 31.2 & 2.7 & 9.0 & 31.2 \\
\hline 4 & 2.1 & 7.0 & 38.9 & 2.1 & 7.0 & 38.8 & 2.3 & 7.6 & 38.9 \\
\hline \multicolumn{10}{|c|}{ Well-being factor distribution } \\
\hline 1 & 1.8 & 29.2 & 29.2 & 1.8 & 29.2 & 29.2 & 1.8 & 29.1 & 29.1 \\
\hline 2 & 1.4 & 23.1 & 52.3 & 1.4 & 23.1 & 52.3 & 1.4 & 23.1 & 52.3 \\
\hline \multicolumn{10}{|c|}{ Self-control factor distribution } \\
\hline 1 & 1.8 & 30.0 & 29.5 & 1.8 & 29.6 & 29.6 & 1.6 & 26.0 & 26.0 \\
\hline 2 & 1.1 & 19.3 & 49.0 & 1.2 & 19.3 & 48.9 & 1.4 & 23.0 & 49.0 \\
\hline 3 & 1.1 & 18.0 & 68.0 & 1.1 & 18.0 & 67.0 & 1.1 & 18.2 & 69.0 \\
\hline \multicolumn{10}{|c|}{ Emotionality factor distribution } \\
\hline 1 & 2.1 & 27.0 & 26.7 & 2.1 & 27.0 & 26.7 & 1.6 & 20.0 & 20.0 \\
\hline 2 & 1.4 & 17.3 & 44.0 & 1.4 & 17.3 & 44.0 & 1.5 & 18.3 & 38.3 \\
\hline 3 & 1.1 & 13.1 & 57.1 & 1.1 & 13.1 & 57.1 & 1.3 & 16.6 & 55.0 \\
\hline
\end{tabular}

\begin{tabular}{|l|l|l|l|l|l|l|l|l|l|}
\hline 4 & 1.0 & 12.6 & 70.0 & 1.0 & 13.0 & 70.0 & 1.2 & 14.8 & 70.0 \\
\hline Sociability factor distribution \\
\hline 1 & 1.7 & 28.3 & 28.3 & 1.7 & 28.3 & 28.3 & 1.7 & 28.2 & 28.2 \\
\hline 2 & 1.4 & 23.5 & 52.0 & 1.4 & 23.5 & 52.0 & 1.4 & 23.7 & 52.0 \\
\hline
\end{tabular}


Considering the structure and idea of trait emotional intelligence the global emotional factor should be a constellation of 4 components. All other factors should be considered as a single unit. As it is shown in table 3 only the global emotional intelligence factor meets this requirement as all other EI facets are consisted of 2-4 components. This means that the remaining facets can not be considered as single, robust facets, rather than a constellation of separate questionnaire items.

\section{Discussion}

In the first part of the discussion separate emotional intelligence factors of highly emotional teachers and this study's sample teachers are being compared. Studies suggest that well-being is a crucial facet for teachers (Taxer, Frenzel, 2015). Such teachers remain positive, are able to boost their student's self-confidence and carry-out their job efficiently. Based on this study's results it can be determined that the well-being score of this sample is valuated slightly above average, but it is also the highest evaluated facet. This means that the teachers from this study's sample are capable of working while maintaining a positive, boosting and motivating state.

When it comes to emotionality, teachers with high emotionality scores are equipped with key skills to be empathetic, take their students' perspective (Mercer, 2016). These kinds of teachers should be able to fully understand their students, help them cope and adapt to various situations. The results of this study revealed that the sample's emotionality factor is evaluated as average. This could mean that the teachers from this sample might be less empathetic, with lesser skills to understand their students or to take their perspective.

A teacher with a high score of self-control puts the understanding of emotions and their consequences first before acting (De Costa et al., 2018). Based on the results of this study it has been revealed that the sample's teachers can be distinguished as having low self-control, hence their self-control score is evaluated below average.

Lastly, sociability for teachers during their job is described as their abilities to interact, control and enjoy various social interactions with their students (Dewaele et al., 2018). Sadly, this study's sample showed the lowest score of sociability. Meaning that the mentioned sample's teachers might not be engaging or effective when it comes to communicating with their students. As mentioned earlier social interactions are significantly important for EI development.

The second part of the discussions reveals how this study's findings correlate with similar research results. Firstly, it is important to mention 
that these scores should be interpreted with caution due to low reliability and factor analysis scores. If, however, we would consider these results as primary or pilot then we could argue that we found similar results to other researchers. Some conducted researches suggest that not only such teachers have a higher emotional intelligence score than general teachers, but also have a higher level of empathy and self-motivation, emotional awareness, emotion management, self-motivation, emotion recognition (Sayko, 2013, Mustaffa, 2018). The analysis that took place during this study was focused towards a broader definition of EI facets. According to the trait emotional intelligence theory emotional intelligence is a constellation of 15 facets, which are merged to 4 major factors mentioned that were mentioned in this study (Petrides et al., 2018). These factors consist the facets that Sayko (2013), Mustaffa, (2018) researched. According to this study's results it is determined that there are several similarities between our findings and those of Savko (2013), Mustaffa, (2018). We found that our samples global EI score and it's factor emotionality (covers empathy and emotion management) scores could be valued at a higher than intermediate level, although the levels of sociability (covers emotion management) are significantly lower than average according to this study. This could mean that this study and the studies carried out by Savko (2013), Mustaffa, (2018) reveal that teachers who work with children who have SEN have higher than average global EI scores and emotionality scores. It is worth to mention that currently there is very little data that exist surrounding this research object, because most of the current research is focused on determine whether or not emotional intelligence scores correlate with other aspects such as job satisfaction, burnout, etc. (Tok, Morali, 2009; Fiorilli, et al., 2019).

These results would be promising if it was considered that the following unreliability of them was partly subjected to: the reseach sample misunderstanding some statements in the questionnaire due to it being written in a foreign language, misplaced or misperceived important notions while answering. After conducting a validity test using the Cronbach's Alpha, it has been clear that the scores are too low to be considered valid. That is why the decision to conduct a KMO factorial analysis has been made. Then it was discovered that only the global EI factor has the required (4) components (factors). According to the trait emotional intelligence theory and it's sampling domain the global EI factor should consist 4 factors, and these 4 factors should be considered as single units (Petrides \& Furnham, 2001). It has been discovered that the 4 factors in this research are not perceived as single units rather than constellations of 2-4 items. It is highly possible that for these reasons this researches scores cannot be considered either valid or significant. They should be perceived as pilot or supportive for more accurate researches. 


\section{Limitations}

During this study there were several limitations. One of the most significant - there was no possibility for eye-to-eye contact during the COVID-19 pandemic. This means that the researcher was unable to fully and immediately answer to any questions related to the research. The second limitation was the language of the questionnaire. Both Lithuanian and Latvian teachers were asked to answer a foreign (English) language questionnaire, which may have led to some item misunderstandings, misinterpretations, etc. Lastly, due to limited time for the planned research a short form of the questionnaire was used. This can hardly count as a limitation, hence this form of the questionnaire is valid and widely used world-wide, but a full form questionnaire may have provided with more detailed insights and results.

\section{Recommendations}

Regarding the experience of this research several improvements should be made. Firstly, the researcher should be more closely involved into the completion of the TEIQue. He should be able to answer all research related questions real time and explain with great detail the content of the questionnaire. Secondly, in order to acquire more accurate data several questionnaires should be used. For example, the TEIQue and the BEIS-10 could offer a broader perception of the research object, aim and research questions.

Although EI development skills were not valuated in this research, teachers who participated in this research are believed to be capable of developing the emotional intelligence of their scholars.

\section{Conclusions}

1. The global emotional intelligence score of the research sample can be partly evaluated as high. The 4 factor scores can be partly evaluated as intermediate - higher than intermediate.

2. The trait emotional intelligence factors of the research sample distribute among themselves from most to least developed as follows: well-being, emotionality, self-control, sociability.

3. As scientific literature would suggest, that teachers who are emotionally more intelligent might be more successful in developing their student's emotional intelligence, hence they are able not only to prosper their own emotional powers, but to help others be more emotionally efficient. 


\section{References}

Alam, A., \& Ahmad, M. (2018). The role of teachers' emotional intelligence in enhancing student achievement. Journal of Asia Business Studies, 12(1), 31-43.

Armour, C. (2012). Mental health in prison: A trauma perspective on importation and deprivation. International Journal of Criminology and Sociological Theory, 5(2), 886-894.

Bar-On, R. (2006). The Bar-On model of emotional-social intelligence (ESI) 1. Psicothema, 13-25.

Boily, R., Kingston, S. E., \& Montgomery, J. M. (2017). Trait and ability emotional intelligence in adolescents with and without autism spectrum disorder. Canadian Journal of School Psychology, 32(3-4), 282-298.

Brackett, M. A., Rivers, S. E., and Salovey, P. (2011). Emotional intelligence: implications for personal, social, academic, and workplace success. Soc. Pers. Psychol. Compass 5, 88-103.

De Costa, P., Rawal, H., \& Li, W. (2018). L2 teachers' emotions: A sociopolitical and ideological perspective. In J. de Dios Martínez Agudo (Ed.), Emotions in second language teaching: Theory, research and teacher education, 71-106. Berlin: Springer.

Dewaele, J.-M. (2018b). Online questionnaires. In A. Phakiti, P. De Costa, L. Plonsky \& S. Starfield (Eds.), Te Palgrave handbook of applied linguistics research methodology, 269-286. Basingstoke: Palgrave Macmillan.

Drigas, A. S., \& Papoutsi, C. (2018). A new layered model on emotional intelligence. Behavioral Sciences, 8(5), 45-63.

Fiori, M., \& Vesely-Maillefer, A. K. (2018). Emotional intelligence as an ability: Theory, challenges, and new directions. In Emotional intelligence in education, 23-47. Berlin: Springer.

Fiorilli, C., Benevene, P., De Stasio, S., Buonomo, I., Romano, L., Pepe, A., \& Addimando, L. (2019). Teachers' burnout: the role of trait emotional intelligence and social support. Frontiers in psychology, 10, 2743.

Gershon, P., \& Pellitteri, J. (2018). Promoting Emotional Intelligence in Preschool Education: A Review of Programs. International Journal of Emotional Education, 10(2), 26-41.

Goleman D. (1995). Emotional Intelligence. New York: Bantam Books.

Grams, S. L., \& Jurowetzki, R. (2015). Emotions in the classroom: the powerful role of classroom relationships. In Dealing with emotions, 81-98. Leiden: Brill Sense.

Gershon, P., \& Pellitteri, J. (2018). Promoting Emotional Intelligence in Preschool Education: A Review of Programs. International Journal of Emotional Education, 10(2), $26-41$.

Humphrey, N., Curran, A., Morris, E., Farrell, P., \& Woods, K. (2007). Emotional intelligence and education: A critical review. Educational Psychology, 27(2), 235-254.

Keefer, K. V., Parker, J. D., \& Saklofske, D. H. (2018). Three decades of emotional intelligence research: Perennial issues, emerging trends, and lessons learned in education: Introduction to emotional intelligence in education. In Emotional intelligence in education, 1-19. Berlin: Springer.

Kumar S. (2013). Emotional Intelligence for Children with Special Needs. International Journal of Scientific Research, 2(4), 63-64. 
Lestari, S. D., \& Sawitri, D. R. (2017). Correlation between emotional intelligence and work engagement of special need school teachers. Advanced Science Letters, 23(4), 3480-3482.

Li, M., Pérez-Díaz, P. A., Mao, Y., \& Petrides, K. V. (2018). A multilevel model of teachers' job performance: Understanding the effects of trait emotional intelligence, job satisfaction, and organizational trust. Frontiers in Psychology, 9, 2420.

Mainhard, T., Oudman, S., Hornstra, L., Bosker, R. J., \& Goetz, T. (2018). Student emotions in class: The relative importance of teachers and their interpersonal relations with students. Learning and Instruction, 53, 109-119.

Mavroveli, S., \& Sánchez-Ruiz, M. J. (2011). Trait emotional intelligence influences on academic achievement and school behavior. British Journal of Educational Psychology, 8(1), 112-134.

Mercer, S. (2016). Seeing the world through your eyes: Empathy in language learning and teaching. In P. D. MacIntyre, T. Gregersen, \& S. Mercer (Eds.), Positive psychology in SLA, 147-167. Bristol: Multilingual Matters.

Mustaffa, D. (2018). Emotional Intelligence of Special Educators and General School Teachers. IJRAR-International Journal of Research and Analytical Reviews 5(2), 532-535.

Parker, J. D., Saklofske, D. H., Wood, L. M., \& Collin, T. (2009). The role of emotional intelligence in education. In Assessing emotional intelligence, 239-255. Boston: Springer.

Petrides, K. V. (2011). Ability and trait emotional intelligence. In T. Chamorro-Premuzic, S. von Stumm, \& A. Furnham (Eds.), The Wiley-Blackwell handbooks of personality and individual differences. The Wiley-Blackwell handbook of individual differences (656-678). Hoboken: Blackwell publishing.

Petrides, K. V. (2017). Intelligence, emotional. Reference Module in Neuroscience and Biobehavioral Psychology, 1(6), 1-6.

Petrides, K. V., \& Furnham, A. (2001). Trait emotional intelligence: Psychometric investigation with reference to established trait taxonomies. European journal of personality, 15(6), 425-448.

Petrides, K. V., Sanchez-Ruiz, M. J., Siegling, A. B., Saklofske, D. H., \& Mavroveli, S. (2018). Emotional intelligence as personality: Measurement and role of trait emotional intelligence in educational contexts. In Emotional intelligence in education, 49-81. New York: Springer.

Poedubicky, V. A., Truene, L., \& Sperlazza, J. (2006). Promoting social and emotional intelligence for students with special needs. Emotionally intelligent school counselling, 125-139.

Romano, L., Tang, X., Hietajärvi, L., Salmela-Aro, K., \& Fiorilli, C. (2020). Students' trait emotional intelligence and perceived teacher emotional support in preventing burnout: the moderating role of academic anxiety. International Journal of Environmental Research and Public Health, 17(13), 4771.

Salovey, P., \& Mayer, J. D. (1990). Emotional intelligence. Imagination, cognition and personality, 9(3), 185-211.

Sayko, K. (2013). Psychological characteristics of emotional intelligence of teachers working with children with developmental disorders. The Journal of Education, Culture, and Society, 4(2), 29-35. 
Siegling, A. B., Saklofske, D. H., \& Petrides, K. V. (2015). Measures of ability and trait emotional intelligence. In Measures of personality and social psychological constructs, 381414. Massachusetts: Academic Press.

Skura, M., \& Świderska, J. (2021). The role of teachers' emotional intelligence and social competences with special educational needs students. European Journal of Special Needs Education, 1-16.

Taxer, J. L., \& Frenzel, A. C. (2015). Facets of teachers' emotional lives: A quantitative investigation of teachers' genuine, faked, and hidden emotions. Teaching and teacher education, 49, 78-88.

Tok, S., \& Morali, S. (2009). Trait emotional intelligence, the big five personality dimensions and academic success in physical education teacher candidates. Social Behavior and Personality: an international journal, 37(7), 921-931.

Valente, S., \& Lourenço, A. A. (2020). Conflict in the classroom: how teachers' emotional intelligence influences conflict management. Frontiers in Education 5(5), 1-10.

Yahyazadeh-Jeloudar, S., \& Lotfi-Goodarzi, F. (2012). Teachers' emotional intelligence and its relationship with job satisfaction. Advances in Education, 1(1), 4-9. 